\title{
Impact of Gas Masks on the Work of Breathing and Breathing Pattern in Subjects With Stable COPD
}

\author{
Stéphane Bourassa, Pierre-Alexandre Bouchard, and François Lellouche
}

\begin{abstract}
BACKGROUND: The gas mask constitutes the main respiratory protective equipment in a chemical, biological, radiological, or nuclear environment. The aim of the study was to evaluate the impact of the gas mask on respiratory pattern, gas exchange, and indexes of respiratory effort in patients with moderate to severe stable COPD. METHODS: Crossover evaluation with 3 randomized-order, 10-min conditions: at rest and with and without a gas mask using 2 different filtered cartridges, each with a distinct inspiratory resistance (cartridge $\mathrm{A}=3.5 \mathrm{~cm} \mathrm{H}_{2} \mathrm{O}$; cartridge $\mathrm{B}=$ $2.2 \mathrm{~cm} \mathrm{H}_{2} \mathrm{O}$, both at $1 \mathrm{~L} / \mathrm{s}$ ). The study involved 8 subjects with COPD, and breathing patterns, indexes of respiratory effort, and capillary blood gases were evaluated. Comparisons of these parameters were made between the tested conditions. RESULTS: Mean subject age was $69 \mathrm{y}$, and mean $\mathrm{FEV}_{1}=1.3 \mathrm{~L}(47 \%$ predicted). Short-term utilization of the gas mask was associated with a significant increase in the indexes of effort in comparison to baseline without a mask. The esophageal product-time product significantly increased in comparison with baseline (cartridge $\mathbf{A}=$ $281 \pm 65 \mathrm{~cm} \mathrm{H} \mathrm{H}_{2} \mathrm{O} / \mathrm{s} / \mathrm{min}$, cartridge $B=253 \pm 47 \mathrm{~cm} \mathrm{H} \mathrm{H}_{2} \mathrm{O} / \mathrm{s} / \mathrm{min}$, and baseline $=184 \pm 46 \mathrm{~cm}$ $\left.\mathrm{H}_{2} \mathrm{O} / \mathrm{s} / \mathrm{min}, P<.001\right)$. There were negligible changes in the breathing pattern and gas exchange. CONCLUSIONS: Indexes of respiratory effort increased slightly in subjects with stable COPD while using a gas mask. This effect was likely related to increased inspiratory resistance when the mask was worn. These data are reassuring for the potential short-duration use of such protection for patients with moderate to severe COPD. Key words: COPD; work of breathing; breathing pattern; gas mask; CBRNE (chemical, biological, radiological, nuclear and explosive); respiratory protective devices. [Respir Care 2019;64(9):1049-1056. () 2019 Daedalus Enterprises]
\end{abstract}

\section{Introduction}

The respiratory system is one of the main entry routes for chemical, biological, radiological, and nuclear agents, and protection is achieved through the use of a gas mask. Gas masks may be used in civilian populations in several situations. In healthy subjects, studies have shown that these protection devices are associated with respiratory distress and increased indexes of effort. ${ }^{1-3}$ The utilization

The authors are affiliated with the Centre de Recherche de l'Institut Universitaire de Cardiologie et de Pneumologie de Québec, Université Laval, Quebec City, Quebec, Canada.

Dr Lellouche has disclosed a relationship with Oxynov, Mr Bourassa has disclosed a relationship with Medical Intelligence CBRNE. The authors have disclosed a relationship with a vocational program for injured $\mathrm{Ca}-$ nadian military members released from the Canadian Armed Forces for medical reasons. of a gas mask in civilian or military patients with COPD may be difficult due to the additional respiratory load. Several studies have evaluated the impact of different inspiratory resistances in gas masks, ${ }^{1,3-10}$ the impact of gas masks on oxygenation and ventilation, ${ }^{11,12}$ the impact of gas masks on comfort $^{5-7,9,10}$ and exercise capabilities, ${ }^{1,3-10}$ and one study evaluated the work of breathing (WOB) related to gas masks. ${ }^{10}$ However, all of these studies were conducted in healthy subjects. There are no data in the literature that evaluate the use of gas masks in subjects with COPD. Thus, the aim of this study was to accurately measure the impact gas masks have

\footnotetext{
Correspondence: François Lellouche MD PhD, Centre de Recherche de l'Institut Universitaire de Cardiologie et de Pneumologie de Québec, 2725, chemin Sainte-Foy, Ville de Québec, Québec, Canada G1V 4G5. E-mail: francois.lellouche@ criucpq.ulaval.ca.
}

DOI: $10.4187 /$ respcare .06550 
on respiratory effort indexes, breathing patterns, and blood gases in subjects with stable COPD.

\section{Methods}

We conducted a randomized controlled crossover study in subjects with stable COPD to evaluate the impact of gas masks. Written consent was obtained from all subjects prior to their participation. The study was conducted at the research center of the Quebec Heart and Lung University Institute, Quebec, Canada. The Research Center Ethics Committee approved this study. Our US Clinical trial registration is NCT02809807 at https://clinicaltrials.gov/.

\section{Subjects}

Inclusion criteria were a diagnosis of stable COPD, $\mathrm{FEV}_{1}$ between $0.30-0.80 \mathrm{~L}$, and no long-term oxygen therapy. The exclusion criteria were claustrophobia, history of esophageal lesions, stroke, or coronary condition. Each subject's medical file was consulted for a valid spirometry test. For those whose test was expired for $\geq 6$ months, a new test was administered prior the subject's inclusion. Typical demographic data (eg, age, gender, weight, height, body mass index) were gathered after inclusion (Table 1).

\section{Protocol}

We tested three 10-min conditions at rest (Fig. 1): without a gas mask, with a gas mask with filtered cartridge A (C7A1, 3M, Brampton, Canada) and with a gas mask with filtered cartridge B (ABD-81, Airboss Defense, Bromont, Canada). The order of the study conditions was randomized with an online tool (https://www.random.org). The same model of gas mask (C4 Gas Mask, Airboss Defense, Bromont, Canada) was used for the entire study. The inspiratory resistance of cartridge A was $3.55 \mathrm{~cm} \mathrm{H}_{2} \mathrm{O}$ at $1 \mathrm{~L} / \mathrm{s}$, and the inspiratory resistance of cartridge $\mathrm{B}$ was $2.21 \mathrm{~cm} \mathrm{H}_{2} \mathrm{O}$ at $60 \mathrm{~L} / \mathrm{min}$. These filtered cartridge resistance values represented the extreme range of the values measured for 8 cartridges tested on the bench. ${ }^{13}$ The internal volume of the mask was $280 \mathrm{~mL}$, and the nose-cup volume was $80 \mathrm{~mL}$, determined with a water-filling technique to measure the different parts of the mask. ${ }^{14}$

To avoid hypoxemia induced by the mask, we delivered additional oxygen using automated flow titration device (FreeO $\mathrm{O}_{2}, \mathrm{Oxynov}$, Quebec, Canada) to maintain a constant $\mathrm{S}_{\mathrm{pO}_{2}}{ }^{15}$ The $\mathrm{S}_{\mathrm{pO}_{2}}$ target was set at the baseline $\mathrm{S}_{\mathrm{pO}_{2}}$ value at steady state for each subject. Between each condition, a washout was done on room air for $10 \mathrm{~min}$.

\section{Physiological Measurements}

Breathing pattern and minute ventilation were determined with pneumotachographs placed at the inspiratory

\section{QUICK LOOK}

\section{Current knowledge}

The respiratory distress experienced by individuals who use gas masks is well known, but it has never been accurately quantified. The resistance of the mask and $\mathrm{CO}_{2}$ rebreathing may increase the work of breathing and oxygen consumption.

\section{What this paper contributes to our knowledge}

In 8 subjects with COPD, the most common population having respiratory insufficiency, we demonstrated the feasibility of safely using a gas mask for a short duration. However, work of breathing was increased in all studied subjects, and oxygen requirements increased for several subjects. Mask design may be improved to reduce the respiratory burden in patients and should include designs to supply oxygen.

and expiratory ports (MP45 $\pm 5 \mathrm{~cm} \mathrm{H}_{2} \mathrm{O}$; Validyne Engineering, Northridge, California); esophageal pressure was recorded using a simple balloon catheter connected to a differential pressure transducer $\left(\mathrm{MP} 45 \pm 100 \mathrm{~cm} \mathrm{H}_{2} \mathrm{O}\right.$; Validyne Engineering). Signals were digitized at $200 \mathrm{~Hz}$ and sampled using an analogic/numeric system (Biopac MP100, Santa Barbara, California). $\mathrm{S}_{\mathrm{pO}_{2}}$ was continuously monitored with an oximeter built into the $\mathrm{FreeO}_{2}$ device, providing one $\mathrm{S}_{\mathrm{pO}_{2}}$ value and the oxygen flow every second. Capillary blood gases were collected at the end of each condition. We measured the mean oxygen needs with masks for each subject, which was continuously recorded with the $\mathrm{FreeO}_{2}$ device. Breathing comfort was assessed based on a visual analog scale (Table 2). ${ }^{16}$ Capillary blood gases were collected from fingertips immediately at the end of each condition and sent within a few minutes to the laboratory for analysis. We used capillary blood gases for $\mathrm{pH}$ and $\mathrm{P}_{\mathrm{aCO}_{2}}$ analysis because they are equivalent to arterial blood gases and do not require arterial puncture. ${ }^{17}$

\section{Data Analysis and Assessment of Subject's Effort}

Subjects' WOB was calculated from esophageal pressure-tidal volume loops, using a Campbell diagram. ${ }^{18-20}$ Respiratory muscle pressure-time product $\left(\mathrm{PTP}_{\mathrm{es}}\right)$ was calculated from the esophageal pressure signal versus time, and esophageal pressure swings $\left(\right.$ Swing $\mathrm{P}_{\mathrm{es}}$ ) were recorded. Analyses were conducted using RESPMAT software as previously described by Maynaud et al. ${ }^{21}$ Auto-PEEP and airway resistance values were also calculated with RESPMAT. We used 10-20 cycles to compute the WOB as usually recommended. ${ }^{18,21-24}$ The 
Table 1. Subject Characteristics at Inclusion

\begin{tabular}{|c|c|c|c|c|c|c|c|c|c|c|c|}
\hline Subject & Gender & $\begin{array}{c}\text { Age, } \\
\text { y }\end{array}$ & $\begin{array}{l}\text { Weight, } \\
\text { kg }\end{array}$ & $\begin{array}{l}\text { Height, } \\
\mathrm{cm}\end{array}$ & $\begin{array}{l}\text { Body Mass } \\
\text { Index, } \mathrm{kg} / \mathrm{m}^{2}\end{array}$ & $\begin{array}{c}\mathrm{FEV}_{1}, \\
\mathrm{~L}\end{array}$ & $\begin{array}{c}\% \text { of } \\
\text { Predicted } \\
\mathrm{FEV}_{1}\end{array}$ & $\mathrm{~S}_{\mathrm{pO}_{2}}, \%$ & $\begin{array}{l}\mathrm{P}_{\mathrm{aCO}_{2}}, \\
\mathrm{~mm} \mathrm{Hg}\end{array}$ & $\mathrm{pH}$ & $\begin{array}{l}\mathrm{HCO}_{3}^{-}, \\
\mathrm{mmol} / \mathrm{L}\end{array}$ \\
\hline 1 & M & 66 & 78.5 & 172 & 26.7 & 2.31 & 72.0 & 94 & 41.5 & 7.42 & 26.1 \\
\hline 2 & M & 68 & 87.1 & 176 & 27.6 & 1.85 & 59.3 & 95 & NA & NA & NA \\
\hline 3 & M & 72 & 97.1 & 173 & 32.6 & 1.33 & 43.0 & 96 & 35.9 & 7.43 & 24.5 \\
\hline $4 *$ & F & 61 & 125 & 157 & 51.0 & 0.84 & 38.0 & 88 & 62.8 & 7.28 & 25.5 \\
\hline 5 & M & 71 & 114 & 188 & 32.5 & 1.89 & 54.3 & 93 & 32.2 & 7.46 & 24.2 \\
\hline 6 & $\mathrm{~F}$ & 70 & 70.3 & 158 & 28.0 & 1.05 & 53.0 & 94 & 39.1 & 7.42 & 25.0 \\
\hline 7 & M & 71 & 88.0 & 163 & 33.1 & 1.08 & 40.0 & 90 & 51.1 & 7.37 & 26.6 \\
\hline 8 & M & 72 & 71.0 & 164 & 26.4 & 0.82 & 30.2 & 93 & 43.4 & 7.38 & 24.4 \\
\hline 9 & M & 74 & 74.0 & 162 & 21.0 & 0.87 & 34.0 & 95 & 43.7 & 7.41 & 26.7 \\
\hline \multicolumn{2}{|c|}{ Mean \pm SD } & $69.4 \pm 3.9$ & $89.4 \pm 19.4$ & $168 \pm 10$ & $31.0 \pm 8.4$ & $1.34 \pm 0.55$ & $47.1 \pm 13.5$ & $93.1 \pm 2.6$ & $43.7 \pm 9.6$ & $7.40 \pm 0.06$ & $25.4 \pm 1.0$ \\
\hline
\end{tabular}

Subjects breathed room air.

* Subject 4 was excluded from the analysis because results available after completion of the study showed clinical instability of arterial blood gases.

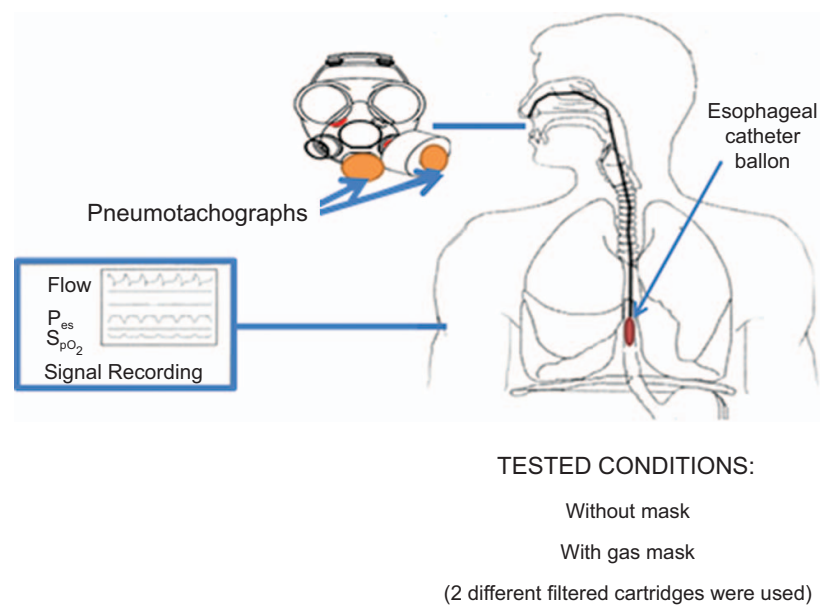

Fig. 1. Experimental setup showing the different measurements taken in subjects with COPD.

esophageal catheter was placed as previously described. ${ }^{24}$ Subjects were evaluated for these parameters with and without the gas mask. When evaluating the condition of subjects with no gas mask, an anesthetic mask was used $(3 \mathrm{M})$.

\section{Statistical Analysis}

Continuous variables were expressed using mean \pm SD. Nominal variables were expressed using percentages. Separate statistical analyses were conducted for our group of COPD subjects. Data were analyzed with a 2 -way mixed model. We defined 2 experimental factors, one related to the comparison between measurements at the baseline, the other to the comparison with or without the gas mask, factors fixed, with interaction terms between the fixed factors. These factors were analyzed as repeated measures
Table 2. Visual Analog Scale

\begin{tabular}{lc}
\hline \hline \multicolumn{2}{c}{ Visual Analog Scale } \\
\hline Very, very comfortable & $10 \mathrm{~cm}$ \\
Very comfortable & 9 \\
Comfortable (satisfying) & 8 \\
Fairly comfortable & 7 \\
Barely comfortable & 6 \\
More or less comfortable & 5 \\
Barely uncomfortable & 4 \\
Fairly uncomfortable & 3 \\
Uncomfortable (but tolerable) & 2 \\
Very uncomfortable & 1 \\
Very, very uncomfortable & $0 \mathrm{~cm}$ \\
& \\
This visual analog scale has been adapted to assess the breathing comfort with a gas mask, \\
with a 10-cm horizontal line marked with "Very, very uncomfortable" at the left end (at $0 \mathrm{~cm}$ ) \\
and marked with "Very, very comfortable" at the right end (at $10 \mathrm{~cm}$ ). A patient marks the \\
comfort level somewhere along the line, with the distance from the left end corresponding to \\
a value in the table.
\end{tabular}

with 2 levels using an unstructured covariance matrix for both factors (one@one). The results were considered significant with $P$ values $\leq .05$. All analyses were conducted by the biostatistician of the research center using SAS/STAT statistical analysis software, version 9.4 (SAS Institute, Cary, North Carolina) and the R Project (Foundation for Statistical Computing, Vienna, Austria).

\section{Results}

\section{Population}

During the study period, 12 COPD out-patients were approached; 2 individuals declined to participate, and another had to withdraw from the study. The remaining 9 subjects participated in and completed the study. One subject 
Table 3. Results of Crossover Examination of 3 Conditions

\begin{tabular}{|c|c|c|c|}
\hline & Without Mask & Cartridge A & Cartridge B \\
\hline \multicolumn{4}{|l|}{ Respiratory parameters } \\
\hline Breathing frequency, min & $16.3 \pm 5.6$ & $15.6 \pm 5.7$ & $16.1 \pm 5.7$ \\
\hline Tidal volume, $\mathrm{L}$ & $0.59 \pm 0.31$ & $0.58 \pm 0.19$ & $0.58 \pm 0.24$ \\
\hline$\dot{\mathrm{V}}_{\mathrm{E}}, \mathrm{L} / \mathrm{min}$ & $8.2 \pm 1.2$ & $8.3 \pm 1.7$ & $8.3 \pm 1.6$ \\
\hline Peak flow, L/s & $0.62 \pm 0.09$ & $0.82 \pm 0.16 \dagger$ & $0.81 \pm 0.11 \dagger$ \\
\hline Inspiratory time, s & $1.68 \pm 0.81$ & $1.91 \pm 1.09 *$ & $1.88 \pm 1.17 *$ \\
\hline Expiratory time, s & $2.55 \pm 1.04$ & $2.59 \pm 1.15$ & $2.56 \pm 1.26$ \\
\hline Total time, s & $4.21 \pm 1.82$ & $4.53 \pm 2.19$ & $4.44 \pm 2.41$ \\
\hline $\mathrm{T}_{\mathrm{I}} / \mathrm{T}_{\text {tot }}, \mathrm{s}$ & $0.39 \pm 0.04$ & $0.42 \pm 0.06$ & $0.42 \pm 0.04$ \\
\hline $\mathrm{V}_{\mathrm{T}} / \mathrm{T}_{\mathrm{I}}, \mathrm{L} / \mathrm{s}$ & $0.35 \pm 0.04$ & $0.34 \pm 0.09$ & $0.33 \pm 0.07$ \\
\hline Auto-PEEP, $\mathrm{cm} \mathrm{H}_{2} \mathrm{O}$ & $2.58 \pm 0.84$ & $3.60 \pm 0.94 \dagger$ & $3.23 \pm 0.57 \dagger$ \\
\hline \multicolumn{4}{|l|}{ Indexes of effort } \\
\hline Work of breathing, J/breath & $0.54 \pm 0.28$ & $0.72 \pm 0.24$ & $0.62 \pm 0.25$ \\
\hline $\mathrm{PTP}_{\mathrm{es}}, \mathrm{cm} \mathrm{H}_{2} \mathrm{O} \cdot \mathrm{s} / \mathrm{min}$ & $184 \pm 45$ & $281 \pm 65 \dagger$ & $253 \pm 47 \dagger$ \\
\hline Swing $\mathrm{P}_{\mathrm{es}}, \mathrm{cm} \mathrm{H}_{2} \mathrm{O}$ & $9.2 \pm 3.0$ & $12.8 \pm 4.1 \dagger$ & $11.8 \pm 2.9 \dagger$ \\
\hline \multicolumn{4}{|l|}{ Capillary gases } \\
\hline $\mathrm{S}_{\mathrm{pO}_{2}}, \%$ & $93.5 \pm 1.9$ & $94.5 \pm 2.2 *$ & $94.3 \pm 2.1 *$ \\
\hline Oxygen flow, $\mathrm{L} / \mathrm{min}$ & 0 & $0.47 \pm 0.98$ & $0.08 \pm 0.13$ \\
\hline $\mathrm{pH}$ & $7.41 \pm 0.03$ & $7.40 \pm 0.03 *$ & $7.41 \pm 0.04 *$ \\
\hline $\mathrm{P}_{\mathrm{aCO}_{2}}, \mathrm{~mm} \mathrm{Hg}$ & $41.0 \pm 6.1$ & $41.8 \pm 6.3^{*}$ & $42.0 \pm 5.8 *$ \\
\hline $\mathrm{HCO}_{3}, \mathrm{mmol} / \mathrm{L}$ & $25.4 \pm 1.1$ & $25.3 \pm 0.9$ & $25.4 \pm 1.0$ \\
\hline \multicolumn{4}{|c|}{ 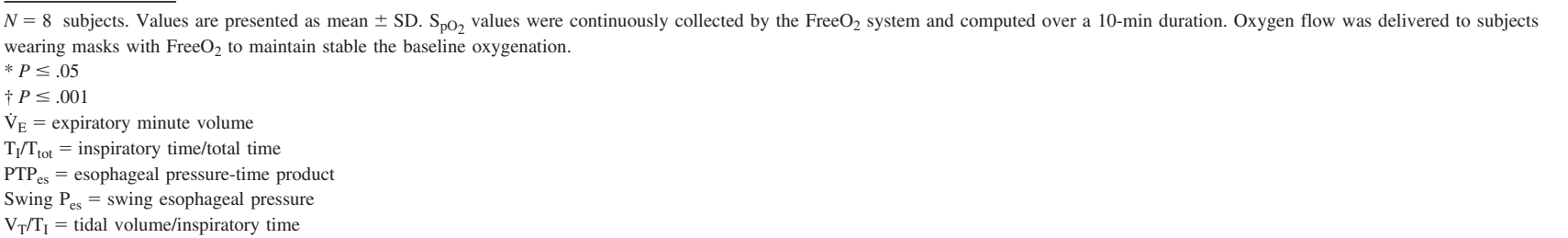 } \\
\hline
\end{tabular}

was not stable at baseline, presenting with respiratory acidosis and was excluded from the main analysis (Table 1).

\section{Indexes of Effort}

Compared to the baseline (ie, the unmasked condition), all respiratory effort indexes increased $15-55 \%$ (Table 3, Fig. 2, and Fig. 3). PTP $\mathrm{es}_{\mathrm{es}}$ and Swing $\mathrm{P}_{\mathrm{es}}$ were significantly increased, while WOB was not significantly increased (PTPes: $P<.001$; Swing $\mathrm{P}_{\mathrm{es}}: P<.001$; WOB: $P=.08$ ). With filtered cartridge $\mathrm{A}$, which had the highest resistance, indexes of effort were all higher than with cartridge B, but the differences were not significant.

\section{Breathing Pattern}

Among respiratory parameters, very little variation was observed between any of the conditions except for the peak flow, which increased by $30 \%$ when a mask was worn (Table 3). There was no difference for other respiratory parameters.

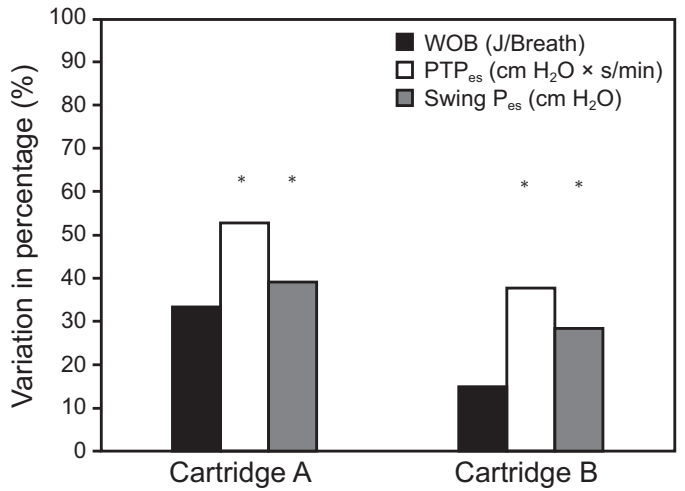

Fig. 2. Variation (\%) in the respiratory effort indexes with filtered cartridge $A$ and filtered cartridge $B$ (with the same gas mask) in comparison to the baseline condition with no mask in subjects with COPD, at rest $(N=8)$. Values are presented as mean \pm SD. In comparing filtered cartridge $B$ vs filtered cartridge $A$, there was no significant differences, and the respective variations were $-15 \%$ for the work of breathing, $-10 \%$ for PTP $_{\text {es }}$, and $-8 \%$ for the Swing $\mathrm{P}_{\text {es }}{ }^{*} P<.001$. 


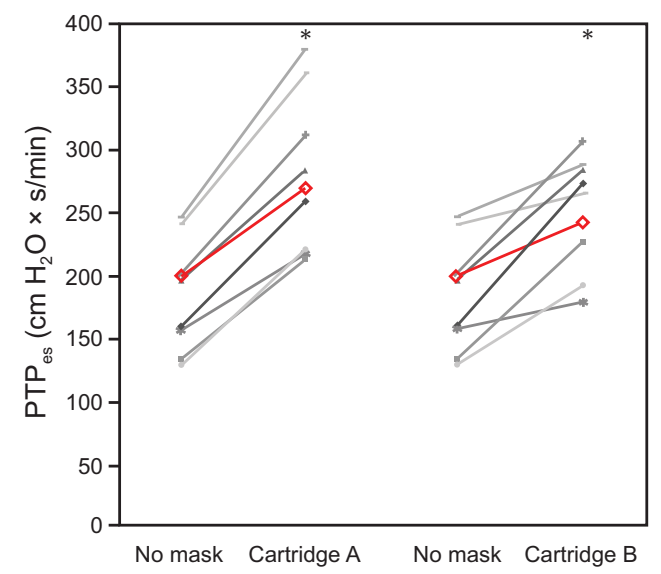

Fig. 3. PTP (cm H2O-s/min) for all subjects with COPD during unmasked and masked comparisons $(N=8)$. Each line denotes a different subject (subject \#4 was excluded); red lines show the median.

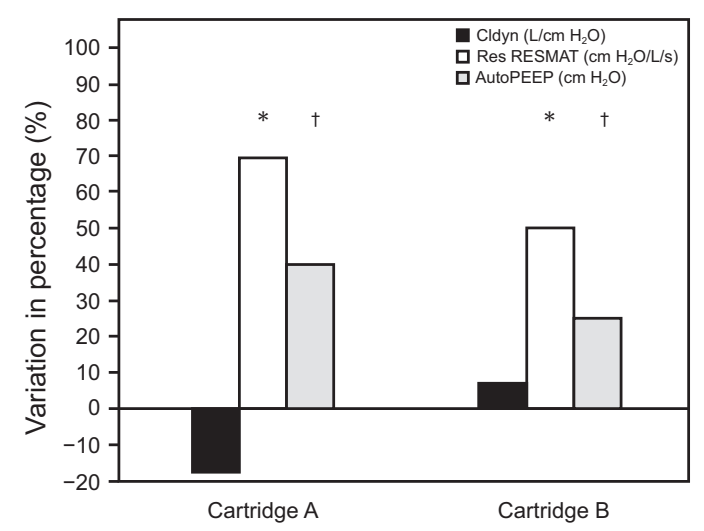

Fig. 4. Variation (\%) in the respiratory compliance, respiratory resistance, and auto-PEEP for filtered cartridge $A$ and filtered cartridge $B$ (with the same gas mask) compared with the unmasked condition in subjects with COPD, at rest $(N=8)$. Values are presented as mean $\pm \mathrm{SD}$. ${ }^{*} P<.05 ; \dagger P<.001$.

\section{Respiratory Mechanics}

Respiratory resistances and intrinsic PEEP values were both significantly increased when a mask was worn (airway resistance at baseline: $8.2 \pm 2.6 \mathrm{~cm} \mathrm{H}_{2} \mathrm{O} / \mathrm{L} / \mathrm{s}$; airway resistance with filtered cartridge A: $13.9 \pm 3.1 \mathrm{~cm} \mathrm{H}_{2} \mathrm{O} / \mathrm{L} / \mathrm{s}$; airway resistance with filtered cartridge $\mathrm{B}: 12.3 \pm 2.8 \mathrm{~cm} \mathrm{H}_{2} \mathrm{O}$; $P=.01$ ) (Table 3, Fig. 4). The variation for the auto-PEEP, dynamic lung compliance, and airway resistances were all increased with masks in comparison to the baseline without a mask (Table 3, Fig. 4).

\section{Gas Exchange}

Differences for $\mathrm{pH}, \mathrm{P}_{\mathrm{aCO}}$, and oxygenation parameters are displayed in the Table 3. In masked conditions, oxygen was administered with the $\mathrm{Free}_{2}$ automated oxygen titration

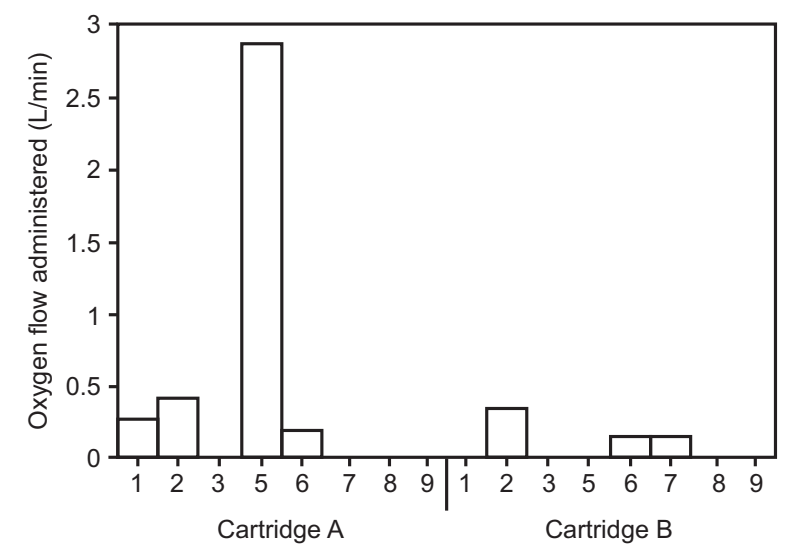

Fig. 5. Mean oxygen flow delivered (L/min) with automated oxygen titration, $\mathrm{FreeO}_{2}$ in subjects with $\mathrm{COPD}$ with filtered cartridge $\mathrm{A}$ and filtered cartridge $B(N=8)$. For each subject, the mean oxygen flow is indicated, both with cartridge $A$ and cartridge $B$.

device to maintain the $\mathrm{S}_{\mathrm{pO}_{2}}$ at a constant level during nearly half of the tested conditions (Fig. 5 and Fig. 6). At baseline, none of the subjects received oxygen therapy. In most subjects, oxygen administration was minimal (ie, no oxygen or below $<0.5 \mathrm{~L} / \mathrm{min}$ ) when masked. The $\mathrm{FreeO}_{2}$ device delivered an average oxygen flow of $0.49 \pm 0.98 \mathrm{~L} / \mathrm{min}$ for cartridge A compared to $0.08 \pm 0.98 \mathrm{~L} / \mathrm{min}$ for cartridge B.

\section{Breathing Comfort}

Comfort was slightly higher without the mask compared to the masked conditions, but the difference was not statistically significant: without mask $7.14 \pm 2.38$ vs filtered cartridge A $5.91 \pm 2.48(P=.19)$; without mask $7.14 \pm 2.38$ vs filtered cartridge B $6.07 \pm 2.08(P=.53)$. When cartridges A and B were compared, comfort values were similar and differences were not statistically significant: $(P=.94)$.

\section{Discussion}

This is the first study to evaluate the impact of wearing a gas mask on indexes of respiratory effort in stable COPD subjects. We found that, in this population, wearing a gas mask increased respiratory effort by $15-55 \%$, but no respiratory distress occurred. Impact on gas exchange as well as oxygen requirements to maintain stable oxygenation was minimal. Given the possibility that civilian subjects may use these protective masks, improving these masks would be necessary to allow them to be worn for prolonged periods in this population.

\section{Impact on Indexes of Respiratory Effort}

In all subjects, we documented an increase in most of the respiratory effort indexes with a gas mask. The in- 

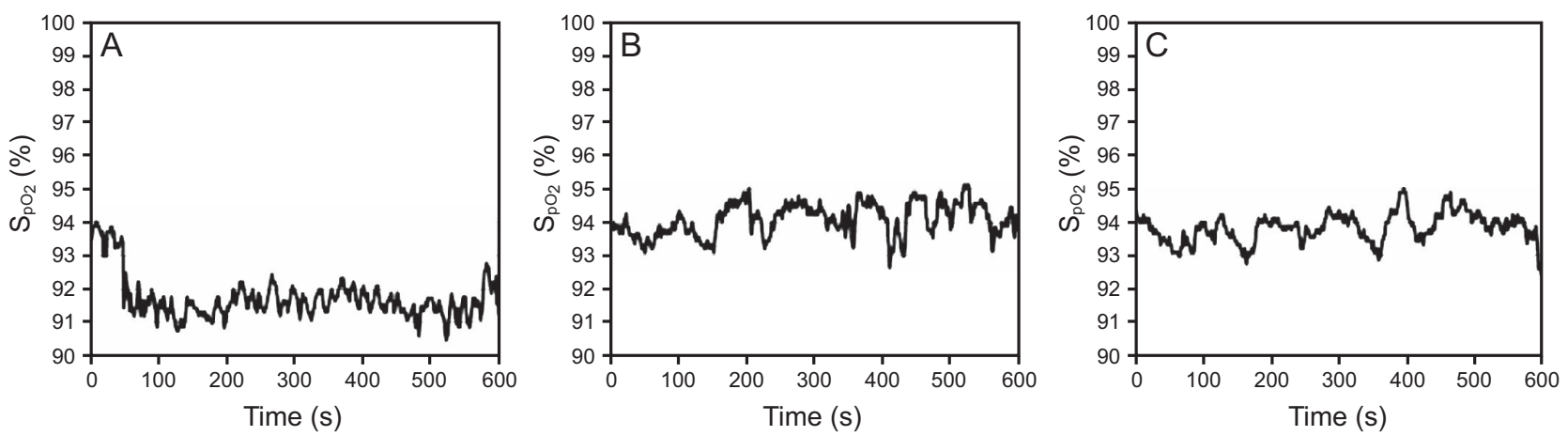

Fig. 6. $\mathrm{S}_{\mathrm{pO}_{2}}$ signal based on a mean among all subjects with COPD for a 10-min duration $(N=8)$. Values are presented as mean $\pm \mathrm{SD}$. A: No mask. B: cartridge A. C: cartridge B.

crease was moderate, and we never had to discontinue the measurements due to respiratory distress. This led us to conclude that the short-term use of a gas mask is feasible for this population. We did not, however, evaluate the impact of wearing gas masks for longer durations. In addition, due to their frailty, we did not evaluate the impact of exercise in these subjects under these conditions, as we have done previously in healthy subjects. ${ }^{3}$

In the literature on gas masks, we conducted the only other study that has included measurements of esophageal pressure with measured indexes of respiratory effort. ${ }^{3} \mathrm{We}$ assessed the impact of wearing a $\mathrm{C} 4$ gas mask in healthy subjects, at rest and during effort, using the same cartridge A. ${ }^{3}$ At rest, the indexes of effort increased by $30-$ $60 \%$ in healthy subjects wearing the mask. In the present study, we found similar increases in subjects with COPD while wearing the same masks.

The administration of oxygen to avoid desaturation may have been a confounding variable. Without supplemental oxygen, the respiratory drive and consequently the respiratory indexes of effort may have been greater. However, only 7 of 16 subjects tested (44\%) required supplemental oxygen. In addition, subjects used very low average oxygen flows (ie, mean oxygen flow was $0.28 \mathrm{~L} / \mathrm{min}$ ). The highest mean oxygen flow was $2.86 \mathrm{~L} / \mathrm{min}$.

\section{Factors Responsible for the Increase in Respiratory Effort}

The increase in respiratory effort can be explained by several factors: resistance, dead space/rebreathing, and intrinsic PEEP. Previous research has found that inspiratory resistance of gas masks may affect the perception of the respiratory distress when wearing a mask. ${ }^{1,2,5,6,9,10}$ In a bench test, we found that total mask resistance was as much as $5.5 \mathrm{~cm} \mathrm{H}_{2} \mathrm{O} / \mathrm{L} / \mathrm{s}$, with the predominant part related to the filtered cartridge. ${ }^{13}$ It is also possible that rebreathing occurs within masks, but as previously discussed, our hypothesis is that the dead space of the mask plays a limited role. The impact of auto-PEEP may also explain in part the increase in respiratory effort, especially in this population with limited expiratory flow. ${ }^{25}$ In fact, auto-PEEP was increased by $25-40 \%$ in our bench test using gas masks. Finally, our hypothesis is that the impact of the resistance predominantly explains the increase in respiratory effort and the respiratory distress described when gas masks are worn. ${ }^{1,2}$ To conclude definitively on the part attributable to rebreathing, an analysis of the gas flow inside the mask during inhalation and exhalation would be required, particularly in the nose cup.

\section{Impact on Ventilation $\left(\mathrm{CO}_{2}\right)$}

There was no clinically relevant effect of the tested conditions on gas exchange in the subjects with COPD in this short-term study. These results contrast with those of Arieli et al, ${ }^{11}$ who found that wearing a gas mask in 9 healthy subjects led to hypoxemia and hypercapnia due to the dead space of the mask and the rebreathing effect. The difference in the internal volume of the masks used in their study and in ours may explain the differences. The internal volume of the mask tested in the study by Arieli et al ${ }^{11}$ was $3.5 \mathrm{~L}$, and the internal volume of the internal mask (ie, the nose cup) was $130 \mathrm{~mL}$. The mask used in our study had smaller volumes $(280 \mathrm{~mL}$ internal volume and $80 \mathrm{~mL}$ for the nose cup). Given the complexity of our experimental setup, we chose not to add measurements of gas composition with our subjects. It is possible, however, that the increase in WOB observed in our subjects is partly related to a certain level of rebreathing effect.

Fraticelli et $\mathrm{al}^{14}$ evaluated the short-term effects of internal volumes of several noninvasive ventilation masks on indexes of respiratory effort, respiratory parameters, and gas exchange. No differences were shown in their comparison with internal volumes up to $980 \mathrm{~mL}$. The dead space of masks during NIV is influenced by the direction of the inspiratory and expiratory flows, and this is likely true with gas masks. The hypothesis was that the internal 
volume of the masks did not reflect the dead space of these devices. ${ }^{14}$ This concept was supported by Fodil et al, who analyzed gas flow distribution within different interfaces. ${ }^{26}$ However, a direct comparison of the $160 \mathrm{~mL}$ dead space of the $\mathrm{C} 4$ gas mask to data from Fraticelli et al ${ }^{14}$ is not possible. Indeed, subjects in that study were assessed in the acute phase of respiratory distress, with noninvasive ventilation and pressure support, whereas our subjects were patients with stable COPD without mechanical support. ${ }^{14}$

\section{Impact on Oxygenation}

We found that, in approximately half of the subjects, oxygen administration was required to maintain baseline oxygenation while wearing the gas mask. We used automated oxygen titration to accurately measure the oxygen requirements in this specific situation. ${ }^{15}$ Our evaluation of oxygen delivery through a gas mask is another original aspect of this work, and there are no equivalent data in the literature. Automated oxygen titration through masks could be adapted to enable its use in a military context that requires the minimization of oxygen consumption for logistical reasons. This study is a continuation of the work previously carried out by Bourassa ${ }^{27}$ on respiratory assistance through gas masks. In addition, accurate titration of oxygen may be required in patients with COPD to avoid hypercapnia induced by hyperoxia. ${ }^{28-30}$

\section{Study Limitations}

We have not fully evaluated the part of the increased respiratory load attributable to the technological dead space of gas masks. Indeed, as discussed above, the internal volume does not correspond directly to the dead space of these devices. Nevertheless, we could not measure the exact internal volume of the masks, the inspired and exhaled fractions of $\mathrm{O}_{2}$ and $\mathrm{CO}_{2}$ from the gases in the mask, nor the respiratory flows within the mask. As a result, we could not assess the precise role played by the mask's dead space in the increase in WOB found in our subjects. Although Fraticelli et al ${ }^{14}$ hypothesized that a mask's dead space plays a limited part in the increase of the WOB, we cannot conclude definitively regarding this aspect.

The use of oxygen within masks may have reduced the overall impact on WOB; however, this allowed the evaluation of the impact of the mask with similar oxygenation levels. In our study, we measured capillary blood gases, not arterial blood gases. There are data in the literature that supports the use of capillary gases as adequate, with excellent correlations for $\mathrm{pH}, \mathrm{P}_{\mathrm{aCO}}$, and bicarbonate. ${ }^{17}$ The number of subjects included in the our study was limited, which reduces the power of the analysis. However, all of our subjects showed similar increases in indexes of effort, and it is likely that more subjects would have yielded similar results. The small sample size may also explain why it was not possible to find statistically significant results for some parameters, such as comparisons for WOB, auto-PEEP, or comfort between filtered cartridge A and cartridge $\mathrm{B}$ (with A being more resistive).

\section{Conclusions}

The short-term utilization of a gas mask in subjects with stable moderate to severe COPD moderately increased respiratory effort indexes without causing respiratory distress. In this population, wearing a gas mask for short periods of 10 min seems safe, and results encourage further clinical research, particularly as it may relate to use when extracting individuals from a situation in which a gas mask is necessary. Moreover, wearing a gas mask had no impact on $\mathrm{P}_{\mathrm{aCO}}$, and we showed the feasibility of delivering oxygen through the gas mask. With respect to pathological respiratory conditions such as COPD, maintaining a subject-specific $\mathrm{S}_{\mathrm{pO}_{2}}$ target was possible with automated oxygen titration. However, prolonged utilization of gas masks may be problematic in this fragile population, and masks with reduced resistances and designs that further reduce rebreathing may be desirable.

\section{ACKNOWLEDGMENTS}

The authors thank Serge Simard for the biostatistics analysis, Major (Retired) Daniel Noebert for reviewing the English language of the article, and Major (Retired) Marc Dauphin MD and Eva Dickson PhD for their mentorship.

\section{REFERENCES}

1. Jetté M, Thoden J, Livingstone S. Physiological effects of inspiratory resistance on progressive aerobic work. Eur J Appl Physiol 1990; 60:65-70.

2. Johnson A, Cummings E. Mask design consideration. Am Ind Hyg Assoc J 1975;36:220-228.

3. Bourassa S, Bouchard PA, Lellouche F. The impact of gas masks on the work of breathing, breathing patterns and gas exchange in healthy subjects. Respir Care 2018;63(11):1350-1359.

4. Kaufman J, Hastings S. Respiratory demand during rigorous physical work in a chemical protective ensemble. J Occup Environ Hyg 2005;2(2):98-110.

5. Johnson AT, Scott WH, Lausted CG, Benjamin MB, Coyne KM, Sahota MS, Johnson MM. Effect of respirator inspiratory resistance level on constant load treadmill work performance. Am Ind Hyg Assoc J 1999;60(4):474-479.

6. Caretti DM, Scott WH, Johnson AT, Coyne KM, Koh F. Work performance when breathing through different respirator exhalation resistances. Am Ind Hyg Assoc J 2001;62(4):411-415.

7. Johnson AT, Scott WH, Lausted CG, Coyne KM, Sahota MS, Johnson MM. Effect of external dead volume on performance while wearing a respirator. Am Ind Hyg Assoc J 2000;61(5):678-684.

8. Heus R, den Hartog EA, Kistemaker LJ, van Dijk WJ, Swenker G. Influence of inspiratory resistance on performance during graded exercise tests on a cycle ergometer. Appl Ergon 2004;35(6):583-590. 


\section{Impact of Gas Masks in Subjects With Stable COPD}

9. Smith G, Bishop P, Beaird J, Ray P, Smith J. Physiological factors limiting work tolerance in chemical protective clothing. Int J Ind Ergon 1994;13:147-155.

10. Caretti DM, Coyne K, Johnson A, Scott W, Koh F. Performance when breathing through different respirator inhalation and exhalation resistances during hard work. J Occup Environ Hyg 2006; 3(4):214-224.

11. Arieli R, Arieli Y, Eynan M, Abramovich A. Use of a fast transcutaneous $\mathrm{CO} 2$ detector to evaluate escape hoods: the "CAPS 2000" with the inlet valves removed from the nose-cup as a test case. Mil Med 2012;177(11):1426-1430.

12. Lucero PF, Nicholson KL, Haislip GD, Morris MJ. Increased airway hyperreactivity with the M40 protective mask in exercise-induced bronchospasm. J Asthma 2006;43(10):759-763.

13. Bourassa S, Lellouche F. Measurement of pressure-flow relationship for the gas mask technology on a bench test. Partitioning of the different components of the mask and comparison of 8 canisters. [Abstract]. CIMVHR Forum 2017;8(suppl):P126.

14. Fraticelli AT, Lellouche F, L’Her E, Taille S, Mancebo J, Brochard L. Physiological effects of different interfaces during noninvasive ventilation for acute respiratory failure. Crit Care Med 2009;37(3): 939-945.

15. Lellouche F, L'Her E. Automated oxygen flow titration to maintain constant oxygenation. Respir Care 2012;57(8):1254-1262.

16. Caretti DW, Whitley JA. Exercise performance during inspiratory resistance breathing under exhaustive constant load work. Ergonomics 1998;41(4):501-511.

17. Zavorsky G, Cao J, Mayo N, Gabbay R, Murias J. Arterial versus capillary blood gases: a meta-analysis. Respir Physiol Neurobiol 2007;155(3):268-279.

18. Tobin JM. Principles and practice of intensive care monitoring. New York: McGraw-Hill; 1998:1525.

19. Akoumianaki E, Maggiore SM, Valenza F, Bellani G, Jubran A, Loring $\mathrm{SH}$, et al. The application of esophageal pressure measurement in patients with respiratory failure. Am J Respir Crit Care Med 2014;189(5):520-531.
20. Mancebo J, Isabey D, Lorino H, Lofaso F, Lemaire F, Brochard L. Comparative effects of pressure support ventilation and intermittent positive pressure breathing (IPPB) in non-intubated healthy subjects. Eur Respir J 1995;8(11):1901-1909.

21. Mayaud L, Lejaille M, Prigent H, Louis B, Fauroux B, Lofaso F. An open-source software for automatic calculation of respiratory parameters based on esophageal pressure. Respir Physiol Neurobiol 2014;192: 1-6.

22. Baydur A, Behrakis P, Zin W, Jaeger M, Milic-Emili J. A simple method for assessing the validity of esophageal ballon technique. Am Rev Respir Dis 1982(128):788-791.

23. Cabello B, Mancebo J. Work of breathing. Intensive Care Med 2006; 32(9):1311-1314.

24. Milic-emili J, Mead J, Turner J. Topography of esophageal pressure as a function of posture in man. J Appl Physiol 1964;19(2): 212-216.

25. Dal Vecchio L, Polese G, Poggi R, Rossi A. "Intrinsic" positive end-expiratory pressure in stable patients with chronic obstructive pulmonary disease. Eur Respir J 1990;3(1):74-80.

26. Fodil R, Lellouche F, Mancebo J, Sbirlea-Apiou G, Isabey D, Brochard L, Louis B. Comparison of patient-ventilator interfaces based on their computerized effective dead space. Intensive Care Med 2010;37(2):193-195.

27. Bourassa $\mathrm{S}$. The use of a gas mask during medical treatment in chemical, biological, radiological, and nuclear environment. Kingston, Ontario: Royal Military College of Canada; 2009;200.

28. Aubier M, Murciano D, Milic-Emili J, Touaty E, Daghfous J, Pariente R, Derenne JP. Effects of administration of O2 on ventilation and blood gases in patients with chronic obstructive pulmonary disease during acute respiratory failure. Am Rev Respir Dis 1980;122: 747-754.

29. Aubier M, Murciano D, Fournier M, Milic-Emili J, Pariente R, Derenne JP. Central respiratory drive in acute respiratory failure of patients with chronic obstructive disease. Am Rev Respir Dis 1980; 122:191-199.

30. O'Driscoll BR, Howard LS, Davison AG. BTS guideline for emergency oxygen use in adult patients. Thorax 2008;63(Suppl 6):1-68.

This article is approved for Continuing Respiratory Care Education credit. For information and to obtain your CRCE

(free to AARC members) visit

www.rcjournal.com

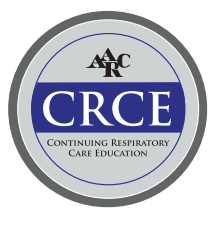

